\title{
INNOVATIVE TECHNOLOGY FOR OBTAINING BIOENERGY THROUGH THE PROCESS OF ADVANCED ANAEROBIC DIGESTION
}

Iulian Voicea, Iuliana Gageanu, Mihai Matache, Valentin Vladut

National Institute of Research-Development for Machines and Installations

Designed to Agriculture and Food Industry, Romania

voicea_iulian@yahoo.com

\begin{abstract}
In many countries, sustainable management, as well as preventing the accumulation and reducing the quantities of waste have become major political priorities, representing an important contribution to the joint efforts to reduce pollution, greenhouse gas emissions and to reduce climate changes at global level. Real actions against global warming represent one of the main priorities of the European energy and environment policies. The European Directives regarding the production of renewable energy, the reduction of GHG emissions and sustainable waste management are based on the commitment of member states to implement adequate measures to fulfil them. The production and use of biogas from anaerobic digestion has the potential to satisfy all the three directives simultaneously. The paper presents an innovative integrated technology for obtaining bioenergy by the means of a mixed system of advanced anaerobic digestion simultaneously in two types of digesters through the process of wet, respectively dry fermentation. The two types of digesters are integrated in a modular system designed and built so that is possible to transport it easily form a micro farm to another. The innovative technology for obtaining biogas through advanced anaerobic digestion will be equipped with a real time command and control system of the methanogenesis process, the necessary energy being ensured by using photovoltaic panels. The results obtained through the innovative technology consisting in a modular system with digesters for wet and dry fermentation of agricultural waste allowed to practically fulfil the concept of farmer energetic independence by using renewable energy sources (biogas, photovoltaic panels, agricultural waste, etc.) and to reduce GHG through the controlled neutralization of important quantities of agricultural waste that otherwise would generate important $\mathrm{CO}_{2}$ quantities into the atmosphere.
\end{abstract}

Keywords: bioenergy, anaerobic digestion, greenhouse gases, organic waste, modular installation.

\section{Introduction}

One of the main environmental problems of today's society is the continuous increase of organic waste. In many countries, sustainable waste management, as well as preventing their accumulation and reducing their quantity have become major political priorities, representing an important contribution to joint efforts for reducing pollution, greenhouse gas emissions and reducing climate changes at global level. Past practices of uncontrolled waste disposal are no longer acceptable today. Even storage on garbage platforms or the incineration of organic waste do not represent the best practices, because environment protection standards have become much stricter nowadays, and energy recovery and the recycling of nutrients and organic matter is a necessity [1;2].

The production of biogas through anaerobic digestion (AD) is considered to be the optimum treatment for manure, as well as for a large variety of organic waste suitable for this purpose, because in this way, the respective substrates are transformed in recoverable energy and in organic fertilizers for agriculture. Simultaneously, by eliminating the organic fraction from the total waste quantity, the stability of remaining waste is increased, as well as the stability of waste dumps [3]. Anaerobic digestion represents a microbiological process of decomposing organic matter in the absence of oxygen, found in many natural environments and applied today at large scale for producing biogas in tank-reactors, usually called digesters, sealed to prevent air from entering. A large variety of microorganisms are involved in the anaerobic process, from which two final products result: biogas and digestate $[4 ; 5]$. Biogas is a combustible gas, consisting of methane, carbon dioxide and small quantities of other gases and microelements. The digestate represents the anaerobically decomposed substrate, rich is macro and micro nutrients and therefore it can be used as fertilizer for plants.

In the recent years, important researches have been conducted on the technologies for converting raw materials into biogas. New types of digesters, feeding systems, storage facilities were introduced and adapted, as well as an entire series of other equipment. Both the system for anaerobic digestion in dry conditions as well as the one in wet conditions are improved continuously, through high level research activities, which are focused both on ensuring the safety of operations and processes, on performances, but also on finding new substrate combinations [6;7]. 
Waste substrates used in the process of anaerobic digestion (AD) can be classified by their origin, the dry matter content (DM), methane yield, and also by other criteria. If these substrates have the dry matter content lower than $20 \%$, they are used for the so called wet digestion (some authors call it wet fermentation). This category includes manure as well as wet organic waste coming from the food industry. When the dry matter content is higher than $35 \%$, the digestion type is called dry digestion (dry fermentation). Dry digestion is typical for energetic crops and for silage materials [8;9].

Choosing the type and quantity of raw material for obtaining the substrate mixture for the process of anaerobic digestion depends on the dry matter content, but also on the content of carbohydrates, fats and proteins. Substrates containing large amounts of lignin, cellulose and hemicellulose can also be co-digested, but in this case, is necessary to apply a pre-treatment, usually in the purpose of loosening compact structures and increasing their digestibility [10].

Currently, the most important application of anaerobic digestion (fermentation) processes is represented by the production of biogas in special installations, by processing substrates from agriculture, such as manure, plant residues, energetic crops or organic waste from agro-industrial activities and from the food industry. It is estimated that at European level there is a considerable potential for increasing the current biogas production, on the basis of zootechnical activities. Following the EU expansion, new Eastern European member states also need to use these technologies and to benefit from their potential for obtaining biogas. The implementation of these anaerobic digestion technologies in these countries will contribute to reducing a large number of environment pollution problems, along with intensifying the sustainable development of rural communities and of the agricultural sector as a whole.

Biogas produced through the methanogenesis process is not expensive and constitutes a renewable energy source, producing, through combustion, neutral $\mathrm{CO}$ and offering the possibility for treating and recycling an extended variety of waste and secondary agricultural products, of various bio-residues, of organic residual waters from the industry, of household waters and sewer sludges, in a sustainable and eco-friendly way. In the same time, biogas brings a large number of social-economic benefits, both for farmers directly involved in producing it, but also for the entire society. Considering all these reasons, biogas resulted through $\mathrm{AD}$ processes constitutes one of the main priorities of the European strategy for biofuels and renewable energy.

\section{Materials and methods}

In order to conduct the experimental tests, an experimental model of modular installation for obtaining bioenergy through advanced dry and wet methanogenesis - MGA, presented in Figure 1, was used. This experimental installation is formed of the modular container, the digester for the process of dry anaerobic digestion (comprised of the percolation system achieved by a recirculating pump and a spraying system with nozzles), the digester for wet anaerobic digestion (has a homogenization system achieved from an agitator with pallets driven by a $1.5 \mathrm{~kW}$ gearmotor). Material feeding is done through the superior part of the digester and the emptying is done through the inferior part. The temperature inside the digester should be maintained constant and, therefore, needs to be constantly monitored. Inside the digester there are a few points for measuring the temperature, in the view of monitoring it throughout the entire process. The measured values are sent to a data recording computer, where they can be visualized. This data input also makes possible to have an automated control of the heating cycle. The $\mathrm{pH}$ value offers important information on the manner how the anaerobic digestion process unfolds.

In order to achieve the proposed goal, the two digesters used for obtaining bioenergy (biogas) through the process of dry respectively wet anaerobic digestion are designed to be fitted with winding pipe inside which the heating liquid coming from the electric boiler of the installation will circulate, and are each equipped with nozzles for fitting 3 temperature sensors, $2 \mathrm{pH}$ sensors, level sensor, biogas flow rate transducer, biogas pressure transducer. Active monitoring and control of digesters is achieved through the means of a PLC connected to a touchscreen operating terminal. The necessary energy for the operation of the modular installation is ensured by a system with photovoltaic panels fitted above the container and equipped with battery group for storing energy. After the fermentation process generates biogas, it is consumed by a biogas generator resulting energy that is stored in the same battery system. 
In Fig. 1, at position $a$ we have the modular container that is a part of the experimental model installation for obtaining bioenergy (biogas) through dry and wet anaerobic fermentation, and the two operators. The container has the following dimensions $L=4270 \mathrm{~mm}, l=2860 \mathrm{~mm}, h=2750 \mathrm{~mm}$, on the roof it has a system of photovoltaic panels with a maximum installed power of $1.5 \mathrm{~kW}$. The energy produced by the photovoltaic panels is stored in special accumulators, being stabilized by a tension inverter, being transformed in $220 \mathrm{~V}$ alternative current. In position $b$ we have the two digesters for the process of dry and wet anaerobic digestion. They are made of fibber glass and are sealed using special silicon sealers. In position $c$ we present the digester for dry anaerobic fermentation, with the possibility to observe the percolation system achieved using 5 nozzles and a pump for recirculating the liquid that is collected at the bottom of the vessel, being designed and fitted with a stainless steel sieve that allows to collect the liquid at the inferior part. At position $d$ we have the digester projection for the process of wet anaerobic fermentation, where we show the classic homogenizing system through the means of an anchor type agitator, driven by a gearmotor. At position $e$ we show the heating system for the installation, achieved throw the means of an electric boiler fed with energy from the photovoltaic panels, along with the system for circulating the heating agent made of two recirculation pumps. At position $f$ in figure 1 we present the command and control box of the modular installation for obtaining bioenergy through advanced dry and wet methanogenesis - MGA.

a)

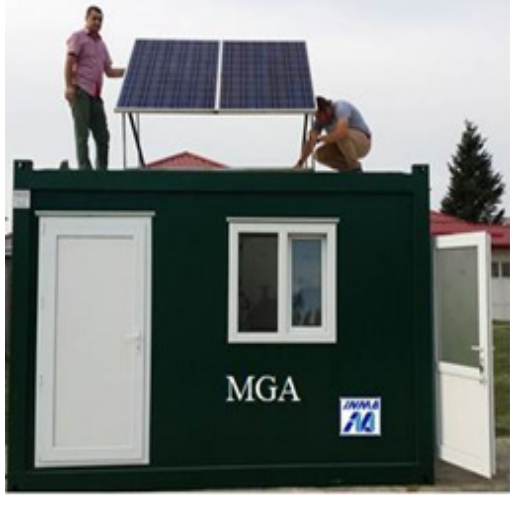

d)

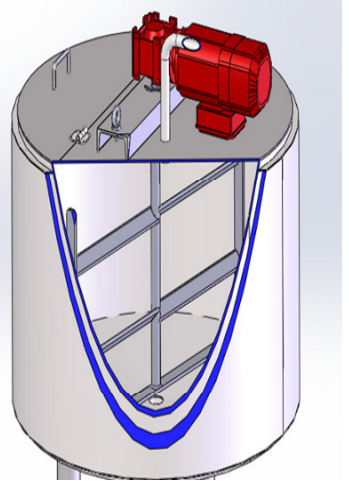

b)

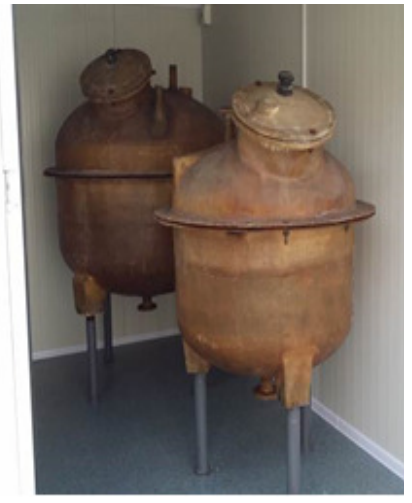

e)

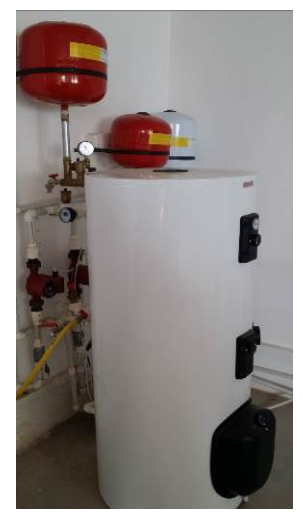

c)

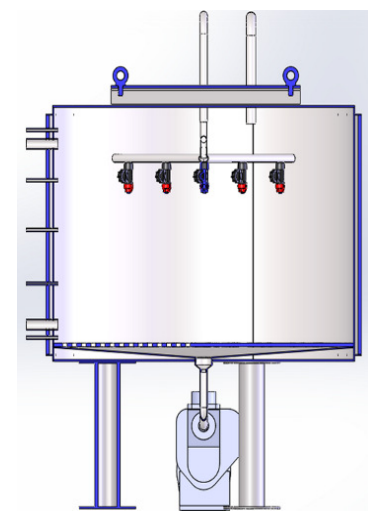

f)

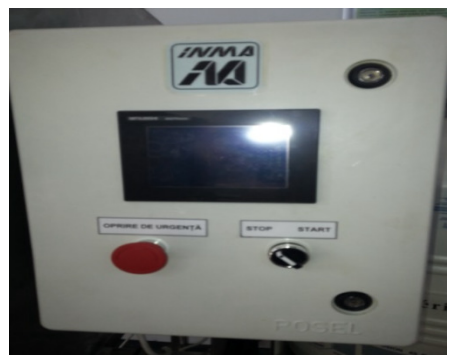

Fig. 1. Experimental model of modular installation for obtaining bioenergy through advanced dry and wet methanogenesis - MGA

The raw material used for the dry anaerobic digestion process was represented by ground miscanthus combined with silage corn. For the process of wet anaerobic digestion, the raw material was represented by manure combined with organic waste from food residues. These materials were used to demonstrate the utility and functionality of this type of low scale biogas installation within a micro agricultural farm. The specific operation of the two bioreactors (digesters), which are a component of the modular installation, is that they have a discontinuous operation, consisting in feeding them with the two types of materials described above, therefore feeding a batch that is subjected to the anaerobic digestion operation that afterwards is completely evacuated, and then a new batch is introduced in the digesters and the process is repeated, thus the anaerobic fermentation type is discontinuous or in batches.

The active control and monitoring of the modular experimental installation for obtaining bioenergy through advanced methanogenesis of agricultural waste (MGA) was achieved using a 
programable logic controller (PLC), programed through the means of a graphic operator interface represented by an operating terminal (OT). Thus, was achieved and integrated software that allows to control the process of wet, respectively dry anaerobic digestion. Through the means of the integrated software, the PLC automatically adjusts:

- the value set for $\mathrm{pH}$, starting the pump that circulates solution for correcting $\mathrm{pH}$, by opening and closing the electro valve corresponding to each reservoir;

- the value set for the fermentation temperature, ensuring the heating of the two digesters until the optimum temperature chosen by the user is reached;

- the homogenisation of the mixture in reactor 1 (process of wet anaerobic digestion), sequentially, at an interval pre-set or set by the operator. The agitating/homogenisation system is represented by an assembly composed of a gearmotor, frequency converter and agitator with pallets;

- the percolation of reactor 2 (process of dry anaerobic digestion). This way, the liquid accumulated and deposed on the bottom part of the container will be percolated by a pump and introduced again in the digester through the means of nozzles;

- the actuations of a vacuum pump and opening an electro valve, allowing biogas accumulation in the reservoir, this being set to be achieved when the pressure of biogas resulted through the processes of dry and wet anaerobic digestion is equal or higher than $0.75-1$ bar, value indicated by the pressure sensor (PT) on the operating terminal (OT).

\section{Results and discussion}

The parameters of the anaerobic digestion process chosen to be monitored and controlled using the installation's automation system were the following ones:

1. temperature of the anaerobic digestion process was $39^{\circ} \mathrm{C}$;

2. $\mathrm{pH}$ of the process was set and maintained at 7 ;

3. retention time in the digesters was 35 days;

4. $\mathrm{C} / \mathrm{N}$ ratio in the two digesters was 20 ;

5. moisture of the mixture in the wet fermentation digester was $92 \%$;

6. moisture of the mixture in the dry fermentation digester was $45 \%$.

Data acquisition was achieved using the dedicate software achieved in the integrated command and control PLC system. Thus, the data is collected in a $c 110$ UHS-I R90 64 GB Performance micro SD memory card, and the file is in Excel format. A new excel file is generated each day, showing the quantity of biogas generated every hour by the digester.

Based on the experimental data collected in the 35 days of the process of digestion or anaerobic was determined trendlines to the evolution of biogas for the wet anaerobic digestion (Fig. 2) that the trendlines for the dry anaerobic digestion (Fig. 3) timber according to the average value the resulting biogas per day in each digester.

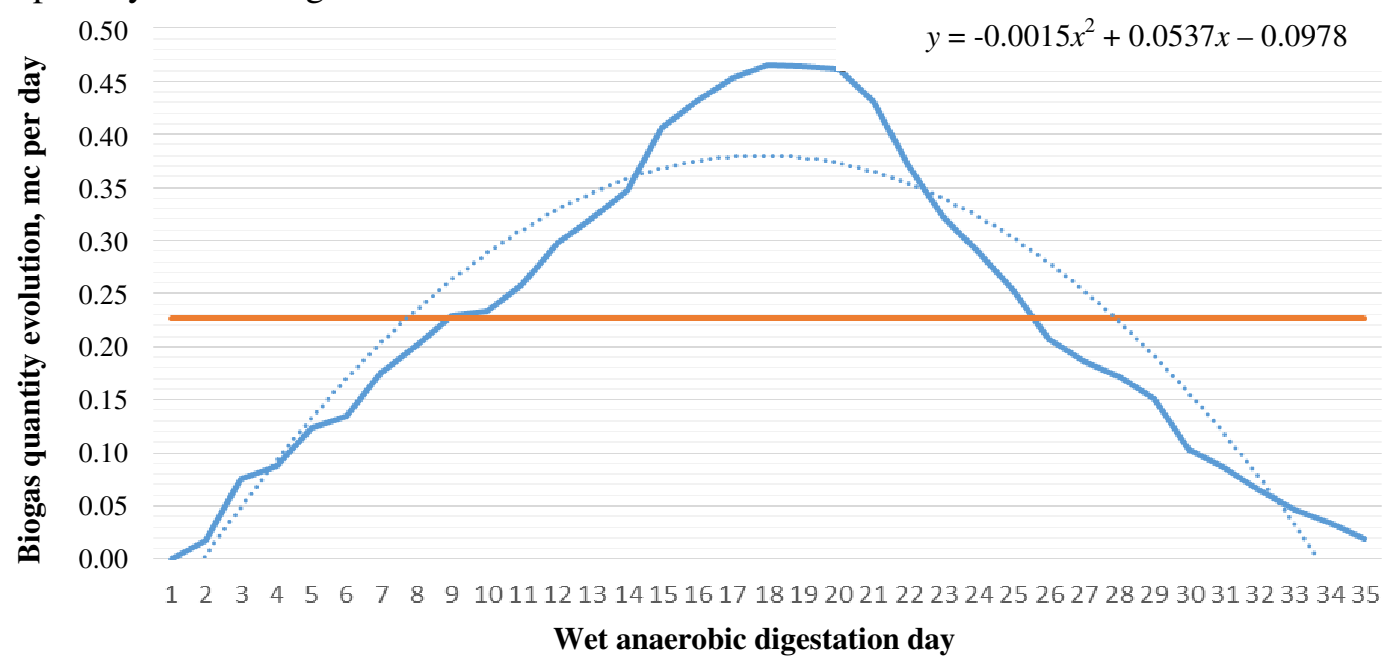

Fig. 2. Trendlines to evolution of biogas for wet anaerobic digestion 


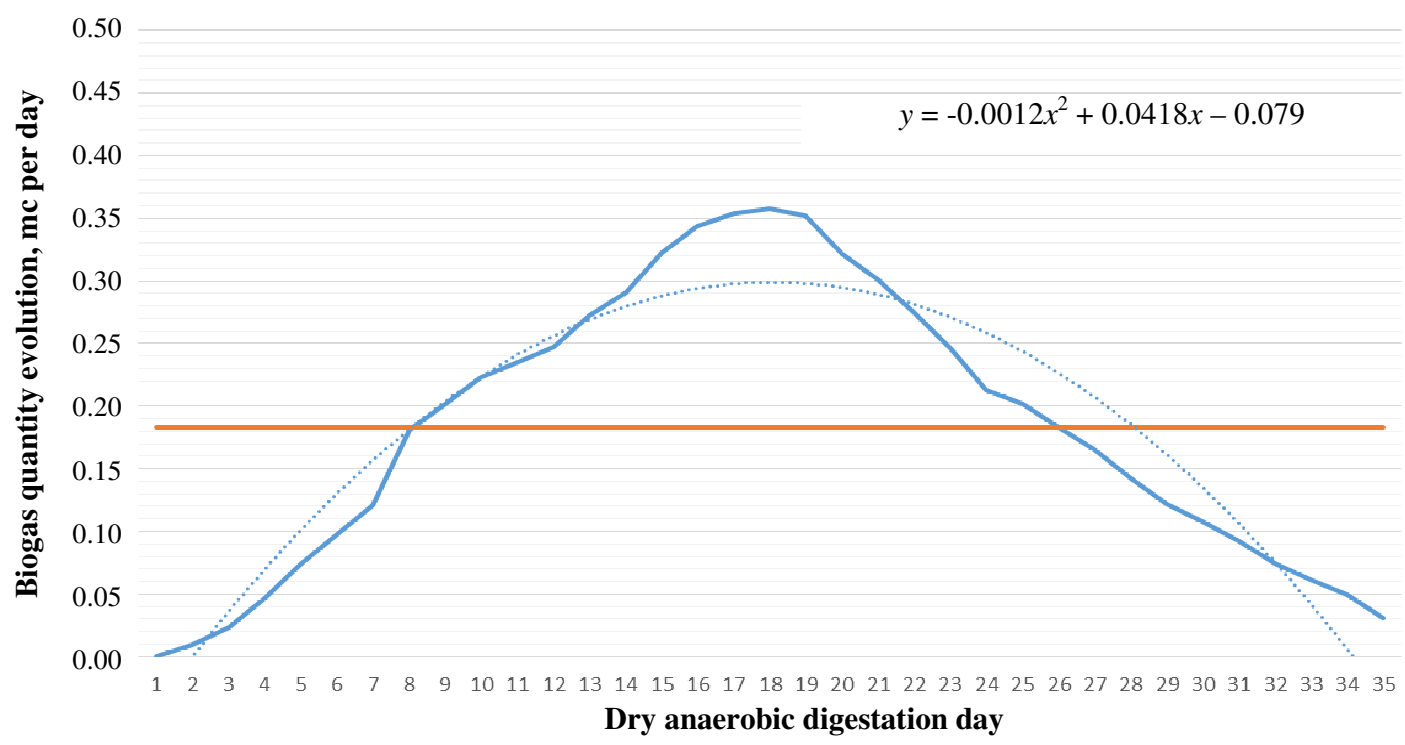

Fig. 3. Trendlines to evolution of biogas for dry anaerobic digestion

\section{Conclusions}

Based on the experimental data, the following conclusions can be given:

1. Wet anaerobic digestion generated a total biogas quantity of $7.921 \mathrm{~m}^{3}$, at an average daily value of $0.226 \mathrm{~m}^{3}$;

2. Dry anaerobic digestion generated a total biogas quantity of $6.418 \mathrm{~m}^{3}$, at an average daily value of $0.183 \mathrm{~m}^{3}$;

3. The biogas resulted showed an adequate $\mathrm{CH}_{4}$ content, allowing it to be successfully combusted in the biogas generator and to be converted into electrical energy used for the energetic independence of the installation;

4. The simultaneous use of both digester types with wet and dry fermentation procedures allows a complex and complete neutralization of agricultural, zootechnical and food waste used as raw materials for the anaerobic digestion process, the installation being completely energetically independent and allowing to reduce the quantity of waste generated by micro agro-zootechnical farms obtaining green energy (biogas) and organic fertilizer (digestate).

\section{Acknowledgement}

This work was funded by the Executive Agency for Higher Education, Research, Development and Innovation Funding, within the project entitled "PN 162404 03: Innovative technology for obtaining biogas through advanced methanogenesis" ctr. 8N/09.03.2016 / Ad. no.1/2017 and "Optimizing the composition of biomass mixtures for obtaining high quality pellets", ctr. 24BG / 2016 (codePN-III-P2-2.1-BG-2016-0266).

\section{References}

1. Ahlberg-Eliasson K., Nadeau E., Leven L., Schnurer A. Production efficiency of Swedish farmscale biogas plants, Biomass and Bioenergy 97 (2017), pp. 27-37;

2. Hejnfelt A., Angelidaki I. Anaerobic digestion of slaughterhouse by-products, Biomass and Bioenergy 33 (8) (2009), pp. 1046-1054;

3. Mata-Alvarez J., Dosta J., Romero-Gueiza M.S., Fonoll X., Peces M., Astals S. A critical review on anaerobic co-digestion achievements between 2010 and 2013, Renewable Sustain. Energy Rev. 36 (2014), pp. 412-427;

4. Demirel B., Scherer P. Trace element requirements of agricultural biogas digesters during biological conversion of renewable biomass to methane, Biomass and Bioenergy 35 (3) (2011), pp. 992-998;

5. Ward A.J., Hobbs P.J., Holliman P.J., Jones D.L. Optimisation of the anaerobic digestion of agricultural resources, BioResources Technology 99 (17), 2008, pp. 7928-7940; 
6. Pucker J., Jungmeier G., Poetsch E.M. Anaerobic digestion of agricultural and other substratesimplications for greenhouse gas emissions, Animal 7 (2013), pp. 283-291;

7. Nielsen - Holm J.B., Seadi T. Al., Oleskowicz-Popiel. The future of anaerobic digestion and biogas utilization, BioResources Technology 100(22), 2012, pp. 5478-5484;

8. Westerholm M., Hansson M., Schnurer A. Improved biogas production from whole stillage by codigestion with catle manure, BioResources Technology 114(2012), pp. 314-319;

9. Hopfner -Sixt K., Amon T., Bodiroza V., Kryvoruchko V., Milanovic D., Zollitsch W. Biogas production from agricultural raw material: characteristics values for assessing material and energy, Landtechnik 61(3) (2006), pp. 148-174;

10. Moeller H.B., Sommer S.G., Ahhring B. Methane productivity of manure, straw and solid fractions of manure, Biomass and Bioenergy 26 (5) (2004), pp. 485-495; 